\title{
Questions under discussion and the semantics/pragmatics divide
}

\section{Article}

Accepted Version

Grindrod, J. and Borg, E. (2019) Questions under discussion and the semantics/pragmatics divide. Philosophical Quarterly, 69 (275). pp. 418-426. ISSN 1467-9213 doi:

https://doi.org/10.1093/pq/pqy058 Available at https://centaur.reading.ac.uk/80434/

It is advisable to refer to the publisher's version if you intend to cite from the work. See Guidance on citing.

To link to this article DOI: http://dx.doi.org/10.1093/pq/pqy058

Publisher: Wiley-Blackwell

All outputs in CentAUR are protected by Intellectual Property Rights law, including copyright law. Copyright and IPR is retained by the creators or other copyright holders. Terms and conditions for use of this material are defined in the End User Agreement.

\section{www.reading.ac.uk/centaur}

\section{CentAUR}

Central Archive at the University of Reading

Reading's research outputs online 
Title: Questions Under Discussion and the Semantics/Pragmatics Divide

Authors: Jumbly Grindrod and Emma Borg.

Address: Philosophy Department, University of Reading, RG6 6AA.

Email: j.grindrod@reading.ac.uk

\begin{abstract}
The 'question under discussion' (or 'QUD') framework is a pragmatic framework that draws on work in the semantics of questions to provide an appealing account of a range of pragmatic phenomena, including the use of prosodic focus in English and restrictions on acceptable discourse moves (Roberts 1996). More recently, however, a number of proposals have attempted to use the framework to help to settle issues at the semantics/pragmatics boundary, fixing the truth-conditions of what is said by a speaker (which many theorists take to be a semantic matter). In this discussion piece, we suggest that this kind of putative extension of the work to be done by the QUD framework is illegitimate, as the framework ultimately seems to depend on a prior grip on semantic content. To see this, we first outline the QUD framework and then raise our concern.
\end{abstract}




\section{Questions Under Discussion and the Semantics/Pragmatics Divide*}

\section{Introduction}

The 'question under discussion' (or 'QUD') framework is a pragmatic framework that draws on work in the semantics of questions to provide an appealing account of a range of pragmatic phenomena, including the use of prosodic focus in English and restrictions on acceptable discourse moves (Roberts 1996). More recently, however, a number of proposals have attempted to use the framework to help to settle issues at the semantics/pragmatics boundary, fixing the truth-conditions of what is said by a speaker (which many theorists take to be a semantic matter). ${ }^{1}$ In this discussion piece, we suggest that this kind of putative extension of the work to be done by the QUD framework is illegitimate, as the framework ultimately seems to depend on a prior grip on semantic content. To see this, we will first outline the QUD framework and then raise our concern.

\section{The QUD framework}

For the purposes of this paper, we will largely draw on the question under discussion framework as developed by (Roberts 1996). The question under discussion can be viewed as an added element of the conversational context that can be appealed to in order to explain particular pragmatic phenomena. Roberts' initial motivation in positing the QUD was to capture the felicity conditions one finds regarding prosodic focus. For example, if we are discussing who ate the brownies, then $1 \mathrm{a}$ is felicitous in a way that $1 \mathrm{~b}$ is not:

1. a) Booker ate the brownies.

b) ?Booker ate the brownies.

While 1a strikes the ear as a perfectly legitimate contribution to the discussion, $1 \mathrm{~b}$ is at risk of sounding infelicitous (although it could be understood as an attempt to change the subject). According to Roberts, this shows that there are felicity conditions that are sensitive to the topic of discussion within a given conversation. In order to capture this, Roberts posits the QUD. On her view, conversation always proceeds with a QUD, whether it is raised explicitly or implicitly, and the QUD will affect the way we can felicitously use focus within a conversation. In particular, the following relationship should hold: use of prosodic focus will be felicitous only if replacing the focused element with an appropriate wh-expression will reveal the active QUD.

Following Hamblin (1973), we can understand questions as denoting a set of propositions that represent possible answers to the question, and we can call this the q-alternative set (or q-alt) for that question. Following Roberts (1996, p. 6), we can obtain the q-alt for a wh-question by abstracting over the wh-phrase, and then applying the resulting open sentence to all appropriate entities within the domain. For instance, suppose that our domain only contains three people Abe, Booker, and Cybil - and for simplicity's sake let's assume that at most one person can drive at a time. We can then represent the q-alt for the question 'Who is driving?' in the following way:

2. [[Who is driving?] $=\mathrm{q}$-alt $\{$ 'Abe is driving', 'Booker is driving', 'Cybil is driving' $\}$

For polar questions, there is no wh-phrase, and so the q-alt consists only of the proposition enquired about:

\footnotetext{
* For discussion of this work, we are grateful to all the participants in the AHRC Research Network 'Pervasive Context', which involved philosophers of language at the University of Reading and at Peking University.

${ }^{1}$ Although see (Borg 2017) for discussion of this claim.
} 
3. $[[$ Is Abe driving?] $]=\mathrm{q}$-alt $\{$ 'Abe is driving' $\}$

This method of generating the q-alt means that in fact not all answers to the question are included, as negative responses (e.g. 'No one is driving' or 'Abe is not driving') are not members of the set. However, this is only a technical detail, as Roberts subsequently makes such answers possible in her definition of answer-hood (Roberts 1996, p. 11)

4. A complete answer to a question contextually entails an evaluation (true or false) for every q-alternative member.

5. A partial answer to a question contextually entails an evaluation (true or false) of at least one q-alternative member.

In this way, an answer such as 'Nobody is driving' can be understood as a complete answer to 2 as it renders all members of the q-alt false. In the same way, 'Abe is not driving' can be understood as a partial answer to 2 and as a complete answer to 3 .

With the notions of partial and complete answerhood in hand, we can also outline a notion of question entailment (Roberts 1996, p. 7):

6. Question entailment: A question $\mathrm{q}_{1}$ entails another question $\mathrm{q}_{2}$ iff a complete answer to $\mathrm{q}_{1}$ yields a complete answer to $\mathrm{q}_{2}$.

We can mark this relation by labelling $\mathrm{q}_{1}$ the superquestion and $\mathrm{q}_{2}$ the subquestion. For instance, 2 entails 3 , and so is a superquestion of 3 . This notion of question entailment is useful not least because Roberts argues that there is usually not just a single QUD in play, but a partially-ordered QUD stack. When we are faced with a given QUD, we can answer it directly if we are able to, or we can form a strategy for obtaining an answer by raising a number of subquestions. This can help us make sense of conversations such as the following:

7. a) Ingrid: Who is driving?

b) Mika: I don't know.

c) Ingrid: I know that Cybil isn't. Is Booker driving?

d) Mika: No.

e) Ingrid: Ok, so Abe is the only that might be driving.

In this example, the initial QUD is raised in 7a. As Mika is unable to provide a (complete) answer, Ingrid asserts that (she knows that) Cybil isn't driving and then raises a subquestion. Mika is able to provide a complete answer to this subquestion, and so the conversation concludes with Ingrid outlining the two answers for the original QUD still available from the context set - that no one is driving or that Abe is driving. This gives some indication of how the QUD could play a number of roles within pragmatic theory - it not only provides some account of the use of focus in English and other languages, but can also provide an account of discourse moves within a conversation. Indeed, much of the point behind Roberts' proposal is to provide a framework that will capture many different pragmatic phenomena, such as presupposition projection, relevance implicatures, and more.

Given the apparent appeal of a framework that captures a range of different pragmatic phenomena, it is a natural step to consider whether the QUD model could be appealed to in accounting for the kinds of cases at the semantics/pragmatics border that have exercised so many theorists in recent years (e.g. (DeRose 2009, Borg 2004, Recanati 2004) to name but a few) and indeed just this kind of step has been taken in some recent works. So, for instance, (Schaffer and Gendler Szabó 2013) argue for a form of epistemic contextualism according to which 
'knowing p' amounts to being able to rule out a contextually-determined set of situations that is partially restricted by the fact that they must be consistent with the presupposition of the QUD. (In this sense, they argue that 'know' is akin to adverbial quantifiers such as 'always' and 'sometimes'.) Their account gives the contextualist-friendly result that the truth-conditional content associated with a knowledge attribution will be dependent upon the QUD that is in play within a given context. So take an utterance of "John knows that Claire stole the diamonds" (call this utterance ' $U$ '). What is required for $U$ to be true will vary across different contexts where different QUDs are in play: if the QUD is 'who stole the diamonds?', then in order for U to be true, John's evidence must rule out all alternatives to Claire stealing the diamonds that are consistent with diamonds being stolen (e.g. ruling out that Abe stole the diamonds, that Booker stole the diamonds, etc). But if the QUD is 'what did Claire steal?', then in order for U to be true, John's evidence must rule out alternatives to Claire stealing the diamonds that are consistent with Claire having stolen something (e.g. ruling out that Claire stole the rubies, that she stole the emeralds, etc). It is the QUD in play, then, that in part fixes the conditions under which an utterance of a knowledge claim is true or false. We see a similar appeal to the QUD in the proposed analysis of what is said put forward by Schoubye and Stokke (2016). Their final analysis of what is said by a sentence defines it as (i) the weakest proposition entailed by or entailing the minimal content of the sentence ${ }^{2}$ and (ii) that constitutes an answer to the QUD. As a result, as the QUD varies, so the q-alt varies, and so the range of propositions from which what is said can be selected varies also. This account delivers the intuitive result that what is said by a sentence can vary across contexts depending on the QUD, as illustrated by 8-9 (we leave it as an exercise for the reader to detail how each [sentence + QUD] pair delivers what is said on each occasion):

8. Sentence: Stokes is ready.

QUD: Who is ready to bat?

What is said: Stokes is ready to bat.

9. Sentence: Stokes is ready.

QUD: Who is ready to bowl?

What is said: Stokes is ready to bowl.

Schaffer and Gendler Szabó's account of knowledge attributions and Schoubye and Stokke's account of what is said both follow a general strategy of attempting to explain features of the semantics/pragmatics divide via appeal to the QUD. It is this general approach that is the target of this paper. In the remainder of the paper, we will argue that such attempts to utilise the QUD framework as part of an account of context-sensitive content - either in the case of a particular expression (as with Schaffer and Gendler Szabó) or as part of a general account of the contextsensitivity of what is said (as with Schoubye and Stokke) - in fact fails to provide the kind of explanation that it purports to.

\section{The small explanatory circle}

The kind of view we are considering is one where the semantic content of a sentence as uttered in context is partly determined by the QUD in play within that context of utterance. In order for

\footnotetext{
${ }^{2}$ Very roughly, the minimal content of the sentence is the context-invariant content associated with the sentence. Following the minimalist view of utterance content, this minimal content can often differ strikingly from what is intuitively said by uttering that sentence. For example, the minimal content of "Steel is strong enough" will be "Steel is strong enough for something", even though the sentence will usually be used to communicate a far more specific proposition; see (Borg 2004, 2012) for much further discussion.
} 
the relevant context-sensitive content to be determined, there must always be an appropriate QUD in play, and an initial worry for this kind of view is that whether there is always a QUD (at a sufficient level of determinacy) is open to question. A first point to note is that, while some discourse does proceed through explicit question-raising and answering, most exchanges are not like this. Theorists often rely upon explicitly-uttered question + answer pairs in order to outline examples of conversations proceeding with a QUD, but we do not have to raise questions explicitly in order for discourse to proceed. Thus if the QUD is a mandatory element of a conversational context, it cannot be determined simply by explicitly-raised questions. Yet, in the case of unspoken QUDs, we might now wonder: is it really the case that discourse always proceeds as an attempt to answer a fully determinate question? Full determinacy cannot be emphasised enough here, because if we allow that the QUD is partially determining truthconditional content, then questions that we wouldn't usually seek to separate from one another in conversation must be separated, as they will lead to different results in what is taken to be literally asserted. For example, consider Schaffer and Gendler Szabó's view that in order for "S knows p" to be true, $S$ must be able to rule out alternatives to $\mathrm{p}$ that are consistent with whatever the QUD presupposes. QUD selection for an utterance like "John knows that Claire stole the diamonds" would then have to be such that it could distinguish between all of the following questions.

10. What did Claire steal?

11. What did Claire steal from De Beers this time?

12. What did Claire do?

13. What did Claire steal using the glass cutters?

Each of (10-13) make different predictions about the relevant alternatives that need to be ruled out for a single utterance of "John knows that Claire stole the diamonds" to be true or false. The initial worry, then, is that in order for a QUD-based view to provide a substantive explanation of context-sensitive semantic content, it must be the case that we can always distinguish between a vast array of possible QUDs in a fine-grained manner. Otherwise, in contexts where no determinate QUD is clearly in play, utterances of the context-sensitive items in question will simply fail to produce determinate truth-conditional content.

In response, advocates of the QUD framework may point to the way in which the QUD is recovered in other implementations of the framework. For instance, Roberts' work on prosodic focus provides us with one clear way to recover the QUD: simply replace the focused element (indicated via prosody in English and other languages) with an appropriate wh-expression, and the resulting question will correspond to the active QUD. We already saw how this works in example (1): replace the stressed element in "Booker ate the brownies" with an appropriate whexpression and we get the right QUD, namely 'Who ate the brownies?'. However, while prosody can provide a useful way of indicating what is at issue in a conversation, it cannot be appealed to as a necessary determinant of the QUD, largely because speakers are not required to use prosodic focus when they speak. So if the QUD is mandatory (as QUD advocates claim it is), but prosodic focus is not, prosodic focus cannot be what determines the QUD in every case. Furthermore, providing an account of how the QUD is fixed in terms of prosodic focus would be, on Roberts' account, to put the cart before the horse. On Roberts' account, prosodic focus is a tool to indicate what question is being answered, not a determinant of the question being 
answered itself. ${ }^{3}$ So in answering the question of how exactly an unspoken QUD is determined within a context, it seems we will have to appeal to something other than the use of prosodic focus and it seems that the options here are pretty limited (ranging from information structure given by things like focus, topic, and co-text, through conversational indicators - such as prosody, demonstrations, and external features like time and location, to the intentional states of the speaker).

Roberts herself is in fact quite explicit that she envisions the QUD framework as intentional in nature: 'I proposed that we model the shared intentions central to discourse structure in terms of a particular type of alternatives: questions' (Roberts 2012, p. 5). On this view, the QUD is fundamentally to be determined by the intentions of the conversational participants, by those questions that they jointly intend to answer upon taking part in the conversation. This kind of intentional view is also suggested by Schaffer \& Gendler Szabó, who, when giving particular examples of QUDs, frequently appeal to what the conversational participants are wondering about. ${ }^{4}$ Combining this intentional view of the QUD with the idea that the QUD is responsible for partly determining context-sensitive semantic content, we arrive at the claim that in order to retrieve the context-sensitive content, we have to first understand what the conversational participants intend to establish within the conversation. Such a view will rest on the empirical conjecture that speakers mentally formulate questions before they speak, questions with a high enough degree of determinacy to guarantee the intuitively correct content for their assertions. Furthermore, it requires that, in order for communicative success to occur, these intentions need to be clearly available to the other conversational participants. We suspect that this empirical conjecture is false. One reason for thinking this is that, if asked, speakers tend not to give the answer the theory demands; as Pupa (2015, p. 285) notes with respect to the parallel idea that speaker intentions are what settle quantifier domain restriction:

In the normal course of events, actual speakers don't intend a particular restriction. When pressed, actual speakers are unwilling or unable to specify a particular restriction. When asked, actual speakers are unlikely to assent to the completions that theorists select on their behalf. ${ }^{5}$

We suggest that the same will hold for the idea that actual speakers are formulating or entertaining questions to be answered whenever they engage in discourse. Of course, this is an empirical conjecture as well and as such remains to be proven by experimentation, and a defender of this approach may well point out that subjects are notoriously bad at retrospective analysis of their own minds (so that an inability to provide the right QUD post facto would not, it might be argued, conclusively show that the subject didn't have the right QUD in mind before they made their utterance). But we would suggest that the burden of proof here lies with those making substantive claims about the mental lives of conversational participants, requiring them to provide positive evidence in favour of the psychological reality of the required QUDs, rather than on those sceptical of such claims.

\footnotetext{
${ }^{3}$ This is consistent with the idea that speakers can indicate that they intend to answer a different question with a use of prosodic focus incongruent with the active QUD.

${ }^{4}$ For instance: '[...] if Ann was wondering who stole the diamonds and then found Claire's fingerprints on the safe, then it would seem true for Ann to say "I know that Claire stole the diamonds". Yet if Ann was instead wondering what Claire stole and then found Claire's fingerprints on the safe, then it would seem false for her to say ["I know that Claire stole the diamonds].' (2013, pp. 491-2).

${ }^{5}$ Italics are Pupa's.
} 
A further problem with appealing to the conversational intentions of speakers in accounting for how the QUD is determined is that it deprives us of a clear method of determining the QUD within any given context. We argue that in absence of such a method, there is a temptation to claim that the QUD will just be that question which provides the basis for deriving the intuitively-expressed content in a given context.

For example, consider how Schoubye and Stokke's account would capture an utterance of "Stokes is ready" in which no explicit QUD has been given, but in a context where the content that we intuitively take the speaker to communicate is that Stokes is ready to bowl. There is a temptation to then claim that the QUD the speaker has in mind must be whatever question it would be that would determine that proposition as what is said (on Schoubye and Stokke's view, this would be: "who is ready to bowl?"). But there is a looming circularity threatening here: this is to use as the key determinant for fixing the QUD the intuitive content of the utterance, but the intuitive content of the utterance is precisely what the QUD framework was brought in to explain. In this sense appealing to the QUD in order to explain context-sensitive content takes us no further in terms of explanation. What we are trying to explain is the intuitive variation in truth-conditional content for some sentence and the suggestion is that this variation is explained and underpinned by variations in the QUD, but now it seems that deciding what the QUD is within a given context implicitly appeals to what the content of a person's utterance is held to be. Now, if a robust account was given of how to retrieve the right QUD, then this would obviously defuse this kind of worry. However, this is a serious undertaking, and our hunch is that when we consider what is required for QUD-fixing, and the limited range of candidates available to play this role, the plausibility of the QUD framework in explaining and capturing issues at the semantics/pragmatics border diminishes. It is for this reason that we are sceptical of the explanatory power of the QUD framework in capturing context-sensitive semantic content. ${ }^{6}$

\section{Conclusion}

To summarise, we think the QUD framework may prove useful in providing an account of certain phenomena such as prosodic focus or discourse moves; it may be, for instance, that when a particular question is conversationally salient, prosodic focus can be used to indicate this. However, we have serious reservations about using the framework to provide a model of how we arrive at semantically relevant content, since the process of fixing the QUD seems to lack the necessary kind of independence from intuitive judgements of what is said.

\section{References}

Borg, Emma. 2004. Minimal Semantics. Oxford: Oxford University Press.

Borg, Emma. 2012. Pursuing Meaning. Oxford: Oxford University Press.

Borg, Emma. 2017. "Explanatory Roles for Minimal Content." Noûs. Online first: doi $10.1111 /$ nous. 12217

\footnotetext{
${ }^{6} \mathrm{~A}$ further interesting aspect of adopting an intention-based view of the QUD is that it then becomes a further question whether explicitly-raised questions obtain the status of being the question under discussion within a conversation. That is, it seems entirely possible that a question could be explicitly uttered within a context and yet the conversational participants do not form the intentions required for that question to become the QUD (crudely, what happens when I say 'Who is ready to bowl?' but think Who is ready to bowl the next ball for England?). This shows that a general account of how the QUD is determined in all cases is required, and not merely in cases where no explicit question has been uttered.
} 
DeRose, Keith. 2009. The Case for Contextualism. Oxford: Oxford University Press.

Hamblin, Charles L. 1973. "Questions in Montague English." Foundations of Language 10 (1):4153.

Pupa, Francesco. 2015. "Impossible interpretations, impossible demands." Linguistics and Philosophy 38 (3):269-287. doi: 10.1007/s10988-015-9169-9.

Recanati, François. 2004. Literal Meaning. Cambridge: Cambridge University Press.

Roberts, Craige. 1996. "Information Structure in Discourse: Towards an Integrated Formal Theory of Pragmatics." Semantics \& Pragmatics 5 (6):1-69.

Roberts, Craige. 2012. "Information structure: Afterword." Semantics and Pragmatics 5 (7):1-19.

Schaffer, Jonathan, and Zoltán Gendler Szabó. 2013. "Epistemic comparativism: a contextualist semantics for knowledge ascriptions." Philosophical Studies 2:491-543.

Schoubye, Anders J., and Andreas Stokke. 2016. "What is Said?" Nô̂s 50 (4):759-793. 